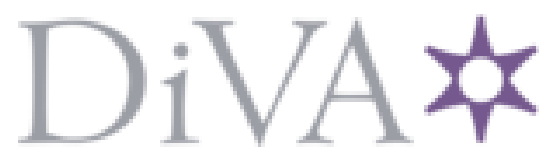

http://www.diva-portal.org

This is the published version of a paper presented at Advances in Computer Entertainment Technology $(A C E)$.

Citation for the original published paper:

Márquez Segura, E. (2015)

Co-creating Embodied Sketches. Playing as a method to design with children..

In: Proceedings of the 12th International Conference on Advances in Computer Entertainment Technology

N.B. When citing this work, cite the original published paper.

Permanent link to this version:

http://urn.kb.se/resolve?urn=urn:nbn:se:uu:diva-271291 


\title{
Co-creating Embodied Sketches. Playing as a method to design with children
}

\author{
Elena Márquez Segura \\ Uppsala University \\ Uppsala, Sweden \\ elena.marquez@im.uu.se
}

\begin{abstract}
Designing body games, games in which the main source of enjoyment comes from bodily engagement, is not an easy task. This article reports on a holistic design approach that considers the social and physical setting of the activity as design resources, together with the technology. We introduce the concept of embodied sketching as a method to gauge how different configurations of resources make for a good design. We report on the experience of using embodied sketching in exploratory workshops with children, as a way to co-create design ideas. The explorations were based on simple games implemented in a technological prototype, which allowed organizers and children to collectively explore game variations by changing the rules of the game, the physical configurations, and the roles of players. We report on our takeaways from four workshops at four different schools in three different countries.
\end{abstract}

\section{Author Keywords}

Play; technology-supported; play engagement; co-located; social; movement-based; interactive toy; Oriboo; sociospatial; embodied sketching; exertion game; body-game.

\section{ACM Classification Keywords}

H.5.m. Information interfaces and presentation (e.g., HCI): Miscellaneous.

\section{INTRODUCTION}

As part of the Kathmandu Kids Workshops organized within the Advances in Computer Entertainment (ACE'12) conference held in Nepal, we organized a co-creation workshop with the goal of promoting creativity and experimentation through exploration and play, as a way to empower local children to actively influence research and design in the domain of entertaining technologies [4]. These workshops were held during the conference in two schools outside Kathmandu, which represented opposing ends of

\footnotetext{
Permission to make digital or hard copies of part or all of this work for personal or classroom use is granted without fee provided that copies are not made or distributed for profit or commercial advantage and that copies bear this notice and the full citation on the first page. Copyrights for thirdparty components of this work must be honored. For all other uses, contact the Owner/Author.

Copyright is held by the owner/author(s).
}

ACE '15, November 16-19, 2015, Iskandar, Malaysia ACM 978-1-45033852-3/15/11. http://dx.doi.org/10.1145/2832932.2832975 the socio-economic spectrum that characterizes Nepal: the Ullens School, a private school with well-equipped classrooms, and the Shree Rudrayanee School, a free school run by the government with very basic facilities [4].

Preliminary observations from ours and similar workshops held in parallel can be found in [4], reporting general impressions about differences and similarities between both schools. Some of these were anticipated, e.g. a higher impact of the novelty effect at Shree Rudrayanee, and a more fluent usage of the technology at the Ullens school. Some similarities were unexpected, e.g. the children's quite similar approach to exploring the mechanisms behind the technology, and how creative they were [4]. We also discussed possible reasons for these observations, such as the difference in exposure and access to technology, the different styles of teaching at both schools, and the difference in English proficiency.

In this paper, we add to our corpus of data with workshops held at two other locations, the Sofia School in Stockholm (Sweden), and the Rico Cejudo School in Seville (Spain). We extended our initial observations in [4] with a detailed video analysis, focused on the identification of interesting play patterns that emerged as a result of the on-the-fly reconfiguration of available design resources by researchers and players. We report on interesting insights that our results yielded, stressing in particular how this form of exploratory workshop, which we call embodied sketching, helps to understand possible configurations of design resources that work to support certain types of play engagement.

\section{BACKGROUND}

We locate our work under the broad umbrella of embodied and gestural interactive games. In this arena, we have witnessed a huge fascination among research and industry regarding new interfaces $[13,14,29,30]$, and a very welcoming response from what became an expansion of the gaming audience. However, the initial thrill dissipated, with a big decrease in purchases of gestural interfaces [7,23]. Initially, the technology limitations were primarily put to blame, with issues like the failure to capture much of our movement repertoire [3]. This brings tensions between what can be 'sensed', what a particular game asks for ('the desired') and our natural and expressive movements ('the expected') [3], which frequently results into solutions that constrains too much the freedom of movements $[21,33]$. 
Research drawing from phenomenological and situated perspectives (e.g.[25]) pin these trade-offs on to positivistic understandings of action - as something that can be specified, represented and modeled, detached from the social context in which the activity unfolds [25].

Yet the 'social factor' is one of the major reasons for players' appeal to multiplayer games [8,10,16,38,39]; It has plenty of positive effects associated, including higher engagement, arousal, affect, and positive emotions $[10,16,27]$.

In addition, we should consider the potential of social and spatial factors for shaping the situated experience, which is well documented $[10,15,18,19]$. However, to this day we are still missing conceptual models, methods and tools for designing meaningful co-located social and physical play.

\section{APPROACHING THE CHALLENGE}

Our approach to addressing the challenges of designing movement-based games is to consider the design space of body-games as something that includes as design resources the technology, as well as socio-spatial elements. Particular examples of such resources are explicit instructions, collective rules negotiation, the arrangement of players, the placement of displays and resources for monitoring of actions and effects, and the spatial configuration of physical and digital objects so that they promote joint action, orientation, monitoring, and interaction.

Designing games with this approach typically involves designing a play activity by distributing tasks and roles that sustain the activity among the parties involved, including both digital and non-digital artifacts and participants. By distributing tasks among different objects and subjects in the space, we also distribute attention in a more balanced way [20] than when the technology sustain the whole activity [40], which usually results in artifact-focused types of interactions [34].

Although we believe in the potential of this holistic approach, in practical terms it adds to the inherent difficulty of designing for play [29].

An important contribution to our work is that by Sturm, Bekker and their group [2,31], researching open-ended designs and their ability to trigger engagement and creativity in children. However, this work does not consider the socio-spatial configuration as design resources. Game design research is also inspirational, with their established range of design experiments, including both evocative and evaluative trials [41], in order to elicit essential design qualities.

\section{EMBODIED SKETCHING}

When we take the socio-spatial configuration into account, different design variations involve different arrangements, tasks, and roles of the available design resources. Over the years, we have developed a method for playtesting this, which we have called embodied sketching.
In embodied sketching, one design resource is fixed, usually a version of the technology, and the sketching centers on in-situ variations with the rest of the design resources at hand. In the particular workshops reported in this paper, we modified and let the participants (children) modify the rest of the design resources to adapt the game to "make it work" in terms of togetherness, playfulness, and fun. The technology that we used was the same as in [21], a hybrid and mobile game platform, the Oriboo (See Fig.1), and two of its implemented games.

\section{The fixed technology resource}

The first game, 'Dance it' (DI) is a goal-oriented game that keeps track of and scores your movements. It is a single player game in which the Oriboo asks you to perform movements (of a repertoire of eight), one after the other. Each well-performed movement adds to the score, and after three movement errors, the game ends. Previous work with the Oriboo shows that DI encourages artifact-focused interaction and static play, due to the way guidance and feedback is presented (through the Oriboo's small display) [34]. In response to this issue we created the second game, "Make My Sound" (MMS), a more explorative game without predefined rules or goals: the Oriboo just plays different music loops in response to qualities of the player's movement. The game is able to distinguish between slow, fast, and jerky movements.

In the workshops, these games were used unchanged. Then, in order to encourage an overall awareness of the social and spatial context around the game, we played variations that introduced changes in the socio-spatial setup. We turned 'Dance it' (DI) into a collaborative multiplayer game in which groups of children, placed along a line or a circle, had to pass one Oriboo within their group. Each child would perform a movement with the device and then pass it to the next player. The difficulty and need to access and share a small display was meant to add a bit of spice to the gameplay. This game was called 'Collaborative Dance it' (Coll-DI). We also created a multi-sided competitive version of the same game, in which two groups would compete with one another in the way described above, to get the highest score (Com-DI for short).

As for 'Make My Sound' (MMS), we planned to playtest three versions. 'Make My Sound - Solo' (MMS-S) was a

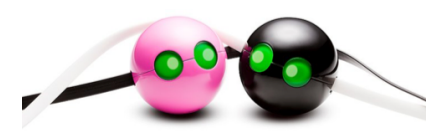

The Oriboo by Movinto Fun is an interactive toy for children, which is able to recognize movement and to provide feedback through light (its two LEDs eyes), sound, and its own movement along its leash. It can be considered a hybrid product in the sense that it is a play device that belongs to the

"intersection of material and digital - traditional toys and digital games" [37]. Picture by Jonas Kullman.

Figure 1. The Oriboo 
single player game in which the children were asked to move so that they triggered one sound of the repertoire. For 'Make My Sound - Group' (MMS-G) the children were grouped and placed in a circle, and they were asked to "sound" like someone else in the group. The final version of this game was 'Make My Sound - blind' (MMS-B), in which the children were blindfolded and told to choose and continuously produce one sound they liked from the repertoire. Then, they had to find their way around the classroom and group with those playing the same sound.

\section{METHOD}

All four workshops followed the same structure: in the middle of the room and covered by a big cloth, we piled up as many Oriboos as children in our workshop. After introducing ourselves, and asking some demographic questions [4], we invited the children to uncover the Oriboos. It followed a time of free play; they could play any of the simple games implemented in the toy. Then, we would play our games, starting with DI and its variants. We recorded the workshops with one static camera to capture an overview of the room, and a moving gopro camera for close-ups.

Data from the workshops were analyzed following a qualitative approach. We first run the videos from the first two workshops, and looked at interesting play patterns that emerged during the workshop. This gave us an initial coding scheme, which was refined based on related work. We observed different types of play that could be related to well-known characterizations of play, like those by Piaget, Zimmerman, and Ermi and Mäyrä [9,26,29,37]. We came up with the categories of challenge-based play, and evocative play. The latter included also sensorimotor play and pretense play. Then we coded moments of immersion and fun, which we then contrasted with Lazzaro's types of fun [17]. Next, we transcribed accounts of key moments of fun, and analyzed them in relation to the games and the socio-spatial configuration, with a particular eye to the players' distribution of attention. We also took notice of different usages of the technology (e.g. different holdings). Finally, we noted moments in which either the researchers or the participants modified the games, paying special attention to how they did so, why, and how this impacted the gameplay.

\section{OUR TAKEAWAYS}

Due to space constrains, we will only focus on elucidating interesting insights that our results yielded, including examples of particular cases that illustrate our points.

\section{Characterizing play}

\section{Classical characterizations fall short}

We found useful to borrow some terms from classical characterizations of play for the coding of play patterns. For example, we characterized play in Rudrayanee and Sofia as mainly sensorimotor and exertion-based; whereas the play activities in Ullens and Rico Cejudo were more competitive (specially at the last school) and challenge-based (See

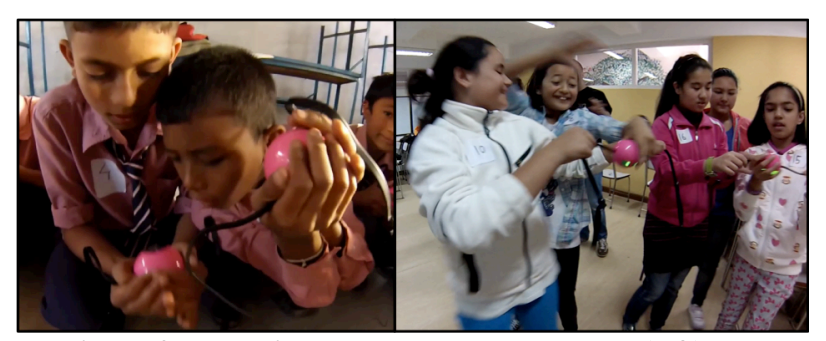

Figure 2. sensorimotor play at Rudrayanee (left) and competitive and challenge-based at Ullens (right)

Fig.2). However, we were reluctant to accept some of the theoretical aspects underpinning these classifications without reservations. For example, the fact that sensorimotor play is characteristic of a 'functional or practice play' stage [26], i.e. that the type of play that we saw in the Rudrayanee and Sofia schools would be indicative of children being in an early development stage. It is true that children in the Sofia school were the youngest in our study groups ${ }^{1}$, but we weren't that comfortable with the implications for the former.

First of all, and although the obvious preference of children at Rudrayanee for exploring the physicality and interactivity of the toy (sensorimotor play), this type of play was also present in the other schools. Like Matusov and Hayes [22], we also question the single directionality of such play phases (in Piaget's theory there is one clear developmental direction (i.e. the child is supposed to "advance" or "progress" from one stage to the next) [22]).

Second, there were obvious communication issues in schools were sensorimotor play was dominant [4]. Finally, at Rudrayanee there was also a very different level of experience with technology compared to other schools, which we think influenced children's gameplay [4], which is not surprising $[1,28]$ - In [1] for example, expert players (children) are shown to be at a likely advantage when playing with novice adult players.

We therefore resonate with critiques to Piaget's theory that draw from a sociocultural perspective, in particular with regards to its universality, its directionality, and its decontextual character [22].

\section{Games as structure}

Taking a design stance, we find useful to see games as designed structures around which play emerges. The shape and interactivity of the Oriboo offers a clear structure around which play unfolds, e.g. children's talking to the toy (Rudrayanee), or competing with their Oriboos to see which one climbs faster (Rico Cejudo), or hitting their friends with the toy (Sofia). We think that the players' understanding of this structure is key for their being able to own and

\footnotetext{
${ }^{1}$ Children at Sofia were 7-8 years old, 11-12 years old at Ullens, 8- 12 at Rudrayanee (fifteen children were older than 10 years old, one child was 8 and another was 9). Finally, everyone at Rico Cejudo was 11 years old.
} 
appropriate their games to suit their needs. Regardless of the complexity of games that the children played, we were able to see appropriation of rules at all four schools, in one way or another: From the girls in Rudrayanee not caring about their scores in one game and freely dancing instead, to the girl who repeated her turn to allow her friend to reach the Oriboo on time at Ullens, to the children at Sofia holding together the Oriboo to play Coll-DI, to the creation of the racing game at Rico Cejudo.

When a game presents a more complex social structure that cannot be enacted unless demonstrated and explained (like our game variations), a good communication with the players is essential. This did not happen at Rudrayanee. Hence, the more complex game variations were discarded and the exercise became focused on games that did not require our mediation. These were games that the children themselves invented that exploited the physical properties of the toy and its interactivity, and therefore involved sensorimotor play.

Regarding classifications of fun, we found useful some recognized terms for labeling behavior. E.g. Using Lazzaro's types of fun, we would characterize all of the sessions as illustrative of people fun, hard fun, and easy fun: We saw many instances of challenge-based immersion, which is characteristic of hard fun, with children overcoming obstacles and trying to score in DI (all the schools), or trying to get the toy to climb faster (Rico Cejudo). There were also many instances of children engaging in open explorative play, characteristic of easy fun. For example, children at Sofia engaged in very expressive and performative moves. Also at Rudrayanee, children were thrilled to explore the shape and function of the Oriboo.

However, these characterizations also overlook important contextual considerations. For example, all of these forms of fun fail to capture the strong social engagement that we observed. E.g. a girl at Ullens, at a time of hard fun with the game DI, interrupted her play to suggest a move to (or to laugh at) another child, or children helping one another, sharing their use of the Oriboo, and laughing together.

What we feel that is missing in these categorizations is a contextual account of the situation, in particular with regards to the socio-spatial configuration of play. We think that future research needs to address more how certain types of fun or modes of play happen and why they happen, and not only the fact that they happen.

\section{Hybridity allows for multiple types of play}

We associate the sensorimotor style of play with a strong focus on the "the affordances for material play - the tactile, spatial and physical experiences it can provide" [35]. Games around the core games implemented in the Oriboo could be considered heavily influenced by the digital material. However, even in those cases, the physical affordances of the toy shaped and influenced the gameplay
- e.g. the way the children negotiated their turn during Coll-DI was as much influenced by the timing implemented in the DI game, as by the fact that the children had hand over the device holding it in a certain way.

We see this tightly tied to the concept of hybrid play in the field of digital gaming and toys [35]. Hybrid toys trigger play experiences with both the digital and the physical material, both of which are intertwined (to a greater or a lesser extent depending on whether these realms are experienced simultaneously, and on how much one depends on the other) [35]. This resonates with a view of the game experience that is not just shaped by the technology, or the artifact, but also by other socio-spatial factors [21].

\section{Embodied sketching as a method}

The exploratory method we employed allowed us to create different idea sketches on the go - understanding sketches as different configurations of roles, tasks, and configurations of technology and players. At Ullens, we saw how the researchers were able to turn the explorative game MMS (children's trying out different sounds) into a challenge-based game, by introducing new rule (children had to keep a smooth type of sound while moving around in the space).

Loads of research has dealt with the concept of flow $[6,36]$, and how to balance challenge and skills so that games are engaging for certain target groups [5,11,12,24,32]. This research typically involves technology implementation, controlled studies experiments, and algorithm tweaking to get to the desired effect. In our workshops, we were able to tweak our games on the fly to make them more engagement and fun, by introducing rules that suited the children's skill. We see in our approach a valuable tool to include early in the design process, avoiding much time and effort in implementation and testing.

Finally, with this type of explorative study, we introduce a very important facet of co-creation with the children. We have seen that, in cases when they were able to understand the designed structure of the activity, they tended to own and change it to their own liking, which is a very valuable asset from a design perspective.

\section{ACKNOWLEDGMENTS}

We thank all the children participating in our workshops, and their teachers. Special thanks to Medin Lamichhane at the Ullens school, Babu Ram Thapa at the Shree Rudrayanee school, Louise Öhnfeldt at the Sofia school, and Lola Segura at the Rico Cejudo school. Also to Carlos Duarte, Adrián Onco, Luis Maqueda, and Mathias Jonsson, who helped me to conduct the workshops. To ACE2012 and Yoram Chisik, who organized the Kids Workshops. To Mobile Life Centre, and Jin Moen, who shipped us with a luggage full of Oriboos around the world. Finally, to Annika Waern and Jon Back for our discussions, which have shaped our understanding of play and playfulness. 


\section{REFERENCES}

1. Helen Bee. 2000. The Developing Child. Pearson, Boston.

2. Tilde Bekker, Janienke Sturm, and Berry Eggen. 2010. Designing Playful Interactions for Social Interaction and Physical Play. Personal Ubiquitous Comput. 14, 5: 385-396. http://doi.org/10.1007/s00779-009-0264-1

3. Steve Benford, Holger Schnädelbach, Boriana Koleva, et al. 2005. Expected, Sensed, and Desired: A Framework for Designing Sensing-based Interaction. ACM Trans. Comput.-Hum. Interact. 12, 1: 3-30. http://doi.org/10.1145/1057237.1057239

4. Yoram I. Chisik, Alissa N. Antle, Brian Birtles, Elena Márquez Segura, and Cristina Sylla. 2014. The Kathmandu Kids Entertainment Workshops. In Entertaining the Whole World, Adrian David Cheok, Anton Nijholt and Teresa Romão (eds.). Springer London, 5-21. Retrieved January 27, 2015 from http://link.springer.com/chapter/10.1007/978-1-44716446-3 2

5. Ben Cowley, Darryl Charles, Michaela Black, and Ray Hickey. 2008. Toward an Understanding of Flow in Video Games. Comput. Entertain. 6, 2: 20:1-20:27. http://doi.org/10.1145/1371216.1371223

6. Mihaly Csikszentmihalyi. 2008. Flow: The Psychology of Optimal Experience. Harper Perennial Modern Classics, New York.

7. Andrei Dobra. Great Games Are Needed to Make PlayStation Move Popular, Sony Admits. softpedia. Retrieved June 7, 2015 from http://news.softpedia.com/news/Great-Games-AreNeeded-to-Make-PlayStation-Move-Popular-SonyAdmits-257838.shtml

8. Nicolas Ducheneaut, Nicholas Yee, Eric Nickell, and Robert J. Moore. 2006. “Alone Together?”: Exploring the Social Dynamics of Massively Multiplayer Online Games. Proceedings of the SIGCHI Conference on Human Factors in Computing Systems, ACM, 407416. http://doi.org/10.1145/1124772.1124834

9. Laura Ermi and Frans Mäyrä. 2005. Fundamental Components of the Gameplay Experience: Analysing Immersion. Retrieved June 7, 2015 from http://summit.sfu.ca/item/260

10. Brian Gajadhar, Yvonne de Kort, and Wijnand IJsselsteijn. 2008. Influence of Social Setting on Player Experience of Digital Games. CHI '08 Extended Abstracts on Human Factors in Computing Systems, ACM, 3099-3104. http://doi.org/10.1145/1358628.1358814

11. Guillermo Gomez-Hicks and David Kauchak. 2011. Dynamic Game Difficulty Balancing for Backgammon. Proceedings of the 49th Annual Southeast Regional Conference, ACM, 295-299. http://doi.org/10.1145/2016039.2016115

12. Robin Hunicke. 2005. The Case for Dynamic Difficulty Adjustment in Games. Proceedings of the 2005 ACM SIGCHI International Conference on Advances in Computer Entertainment Technology, ACM, 429-433. http://doi.org/10.1145/1178477.1178573

13. Katherine Isbister and Kaho Abe. 2015. Costumes As Game Controllers: An Exploration of Wearables to Suit Social Play. Proceedings of the Ninth International Conference on Tangible, Embedded, and Embodied Interaction, ACM, 691-696. http://doi.org/10.1145/2677199.2688813

14. Katherine Isbister, Rahul Rao, Ulf Schwekendiek, Elizabeth Hayward, and Jessamyn Lidasan. 2011. Is More Movement Better?: A Controlled Comparison of Movement-based Games. Proceedings of the 6th International Conference on Foundations of Digital Games, ACM, 331-333. http://doi.org/10.1145/2159365.2159429

15. Esther Jakobs, Antony S. R. Manstead, and Agneta H. Fischer. 1996. Social context and the experience of emotion. Journal of Nonverbal Behavior 20, 2: 123 142. http://doi.org/10.1007/BF02253073

16. Yvonne A. W. De Kort and Wijnand A. Ijsselsteijn. 2008. People, Places, and Play: Player Experience in a Socio-spatial Context. Comput. Entertain. 6, 2: 18:118:11. http://doi.org/10.1145/1371216.1371221

17. Nicole Lazzaro. 2004. Why we Play Games: Four Keys to More Emotion without Story.

18. Carsten Magerkurth, Timo Engelke, and Maral Memisoglu. 2004. Augmenting the Virtual Domain with Physical and Social Elements: Towards a Paradigm Shift in Computer Entertainment Technology. Comput. Entertain. 2, 4: 12-12. http://doi.org/10.1145/1037851.1037870

19. Antony Stephen Reid Manstead. 2005. The social dimension of emotion. The Psychologist 18, 8: 484487.

20. Elena Márquez Segura and Katherine Isbister. 2015. Enabling Co-Located Physical Social Play: A Framework for Design and Evaluation. In Game User 
Experience Evaluation, Regina Bernhaupt (ed.). Springer International Publishing, 209-238.

21. Elena Márquez Segura, Annika Waern, Jin Moen, and Carolina Johansson. 2013. The Design Space of Body Games: Technological, Physical, and Social Design. Proceedings of the SIGCHI Conference on Human Factors in Computing Systems, ACM, 3365-3374. http://doi.org/10.1145/2470654.2466461

22. Eugene Matusov and Renee Hayes. 2000. Sociocultural critique of Piaget and Vygotsky. New Ideas in Psychology 18, 2-3: 215-239. http://doi.org/10.1016/S0732-118X(00)00009-X

23. Angela Moscaritolo. Microsoft: Xbox One Sales Double After Dropping Kinect. PCMAG. Retrieved June 7, 2015 from http://www.pcmag.com/article2/0,2817,2461023,00.as $\mathrm{p}$

24. Lennart Nacke and Craig A. Lindley. 2008. Flow and Immersion in First-person Shooters: Measuring the Player's Gameplay Experience. Proceedings of the 2008 Conference on Future Play: Research, Play, Share, ACM, 81-88. http://doi.org/10.1145/1496984.1496998

25. Kenton O'hara, Richard Harper, Helena Mentis, Abigail Sellen, and Alex Taylor. 2013. On the Naturalness of Touchless: Putting the "Interaction" Back into NUI. ACM Trans. Comput.-Hum. Interact. 20, 1: 5:1-5:25. http://doi.org/10.1145/2442106.2442111

26. Jean Piaget. 1962. Play Dreams \& Imitation in Childhood. W. W. Norton \& Company, New York.

27. Niklas Ravaja, Timo Saari, Marko Turpeinen, Jari Laarni, Mikko Salminen, and Matias Kivikangas. 2006. Spatial Presence and Emotions During Video Game Playing: Does It Matter with Whom You Play? Presence: Teleoper. Virtual Environ. 15, 4: 381-392. http://doi.org/10.1162/pres.15.4.381

28. Kenneth H. Rubin, Terrence L. Maioni, and Margaret Hornung. 1976. Free Play Behaviors in Middle- and Lower-Class Preschoolers: Parten and Piaget Revisited. Child Development 47, 2: 414-419. http://doi.org/10.2307/1128796

29. Katie Salen and Eric Zimmerman. 2003. Rules of Play: Game Design Fundamentals. The MIT Press, Cambridge, Mass.

30. Bart Simon. 2009. Wii are Out of Control: Bodies, Game Screens and the Production of Gestural Excess.
Social Science Research Network, Rochester, NY. Retrieved June 7, 2015 from http://papers.ssrn.com/abstract $=1354043$

31. Janienke Sturm, Tilde Bekker, Bas Groenendaal, Rik Wesselink, and Berry Eggen. 2008. Key Issues for the Successful Design of an Intelligent, Interactive Playground. Proceedings of the 7th International Conference on Interaction Design and Children, ACM, 258-265.

http://doi.org/10.1145/1463689.1463764

32. Penelope Sweetser and Peta Wyeth. 2005. GameFlow: A Model for Evaluating Player Enjoyment in Games. Comput. Entertain. 3, 3: 3-3. http://doi.org/10.1145/1077246.1077253

33. Joshua Tanenbaum and Karen Tanenbaum. 2015. Envisioning the Future of Wearable Play: Conceptual Models for Props and Costumes as Game Controllers.

34. Jakob Tholander and Carolina Johansson. 2010. Design Qualities for Whole Body Interaction: Learning from Golf, Skateboarding and BodyBugging. Proceedings of the 6th Nordic Conference on HumanComputer Interaction: Extending Boundaries, ACM, 493-502. http://doi.org/10.1145/1868914.1868970

35. Heikki Tyni, Annakaisa Kultima, and Frans Mäyrä. 2013. Dimensions of Hybrid in Playful Products. Proceedings of International Conference on Making Sense of Converging Media, ACM, 237.

36. JT Velikovsky. 2014. Flow Theory, Evolution \& Creativity: Or, "Fun \& Games." Proceedings of the 2014 Conference on Interactive Entertainment, ACM, 23:1-23:10. http://doi.org/10.1145/2677758.2677770

37. Irina Verenikina, Pauline Harris, and Pauline Lysaght. 2003. Child's Play: Computer Games, Theories of Play and Children's Development. Proceedings of the International Federation for Information Processing Working Group 3.5 Open Conference on Young Children and Learning Technologies - Volume 34, Australian Computer Society, Inc., 99-106.

38. Amy Voida, Sheelagh Carpendale, and Saul Greenberg. 2010. The Individual and the Group in Console Gaming. Proceedings of the 2010 ACM Conference on Computer Supported Cooperative Work, ACM, 371-380. http://doi.org/10.1145/1718918.1718983

39. Amy Voida and Saul Greenberg. 2009. Wii All Play: The Console Game As a Computational Meeting Place. Proceedings of the SIGCHI Conference on Human Factors in Computing Systems, ACM, 1559- 
1568. http://doi.org/10.1145/1518701.1518940

40. Annika Waern. 2009. Information Technology in Pervasive Games. In Pervasive Games, Markus Montola, Jaakko Stenros and Annika Waern (eds.). Morgan Kaufmann, Boston, 163-174.
41. Annika Waern and Jon Back. 2015. Experimental Game Design. In Game Research Methods: An Overview, Patri Lankoski and Staffan Björk (eds.). Lulu.com, 341-353. 